\title{
MARGINAL QUANTILES FOR STATIONARY PROCESSES
}

Yves bominicy, siegfrie d Hormann. Giroaki ogata and Davio veredas.

Documentos de Trabajo. N. 1228

\section{banco es españa}

\author{
Eurosistema
}


MARGINAL QUANTILES FOR STATIONARY PROCESSES 
MARGINAL QUANTILES FOR STATIONARY PROCESSES

\author{
Yves Dominicy ${ }^{(*)}$, Siegfried Hörmann ${ }^{(*)}$ and David Veredas ${ }^{(* *)}$ \\ UNIVERSITÉ LIBRE DE BRUXELLES \\ Hiroaki Ogata ${ }^{(* * *)}$ \\ WASEDA UNIVERSITY
}

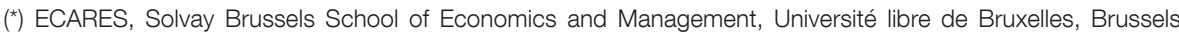
Belgium; email: yves.dominicy@ulb.ac.be.

$\left.{ }^{* *}\right)$ Department of Mathematics, Université libre de Bruxelles, Brussels, Belgium; email: siegfried.hormann@ulb. ac.be.

$\left.{ }^{(* \star *}\right)$ ECARES, Solvay Brussels School of Economics and Management, Université libre de Bruxelles, Brussels, Belgium; email: david.veredas@ulb.ac.be.

This article was written while David Veredas was visiting the Department of Monetary and Financial Studies at the Banco de España (Madrid, Spain), and Yves Dominicy was at the School of Operations Research and Information Engineering at Cornell University (Ithaca, New York, USA). Yves Dominicy acknowledges financial support from a F.R.I.A. grant. Siegfried Hörmann acknowledges financial support from the Communauté française de BelgiqueActions de Recherche Concertées (2010-2015). Hiroaki Ogata acknowledges financial support of Grant-in-Aid for Young Scientists (B), 22700291. Yves Dominicy and David Veredas are members of ECORE, the association between CORE and ECARES. Any remaining errors an inaccuracies are ours.

Corresponding address: Siegfried Hörmann, Départment de Mathématique, Université libre de Bruxelles, CP215, Boulevard du Triomphe, B1050 Brussels, Belgium. Phone: +3226505886. Fax: 3226505867

$\left.{ }^{(\star \star \star}\right)$ School of International Liberal Studies, Waseda University, Tokyo, Japan; email: hiroakiogata@aoni.waseda.jp 
The Working Paper Series seeks to disseminate original research in economics and finance. All papers have been anonymously refereed. By publishing these papers, the Banco de España aims to contribute to economic analysis and, in particular, to knowledge of the Spanish economy and its international environment.

The opinions and analyses in the Working Paper Series are the responsibility of the authors and, therefore, do not necessarily coincide with those of the Banco de España or the Eurosystem.

The Banco de España disseminates its main reports and most of its publications via the INTERNET at the following website: http://www.bde.es.

Reproduction for educational and non-commercial purposes is permitted provided that the source is acknowledged.

C BANCO DE ESPAÑA, Madrid, 2012

ISSN: 1579-8666 (on line) 


\section{Abstract}

We establish the asymptotic normality of marginal sample quantiles for S-mixing vector stationary processes. S-mixing is a recently introduced and widely applicable notion of dependence. Results of some Monte Carlo simulations are given.

Keywords: Quantiles, S-mixing.

JEL classification: C01. 


\section{Resumen}

Establecemos la normalidad asintótica de cuantiles muestrales marginales para un proceso vectorial estacionario S-mixing, una noción de dependencia recientemente propuesta y que cubre un amplio rango de procesos temporales. También mostramos resultados de una simulación de Monte Carlo.

Palabras clave: cuantiles, S-mixing.

Código JEL: C01 


\section{Introduction}

Let us assume that $\left\{\boldsymbol{X}_{t}, t \in \mathbb{Z}\right\}$ is a strictly stationary and ergodic $p$-variate process. We denote by $X_{t}^{(i)}$ the $i$-th component of $\boldsymbol{X}_{t}$ with marginal distribution function $F^{(i)}(x)=$ $P\left(X_{t}^{(i)} \leq x\right)$, and $\tau$-quantile $q_{\tau}^{(i)}=\inf \left\{x \mid F^{(i)}(x) \geq \tau\right\}$. Analogously, let

$$
F_{n}^{(i)}(x)=\frac{1}{n} \sum_{k=1}^{n} I\left\{X_{k}^{(i)} \leq x\right\}
$$

be the $i$-th marginal empirical distribution function and denote the empirical $\tau$-quantile by

$$
q_{\tau, n}^{(i)}=\inf \left\{x \mid F_{n}^{(i)}(x) \geq \tau\right\} .
$$

The aim of this note is to investigate the asymptotic behaviour of the marginal sample quantiles for $p$-dimensional stationary processes $\left\{\boldsymbol{X}_{t}\right\}$ and obtain the asymptotic normality of the empirical quantile vector $\left(q_{\tau_{1}, n}^{(1)}, \ldots, q_{\tau_{p}, n}^{(p)}\right)^{\prime}$ for given $\tau_{1}, \ldots, \tau_{p} \in[0,1]$.

Asymptotic properties of sample quantiles have been of great interest since Cramér (1946) [5] gave the joint asymptotic normality of sample quantiles coming from an independent and identically distributed (i.i.d.) univariate population. Babu and Rao (1988) [1] derived the joint asymptotic normality of marginal sample quantiles coming from an i.i.d. multivariate population. In the case of dependent processes, Sen (1968) [14] extended the results of Bahadur (1966) [2] to $m$-dependent stochastic processes and showed the asymptotic normality of sample quantiles. Duta and Sen (1971) [8] extended those results to show the asymptotic normality of sample quantiles for multivariate autoregressive processes. Sen (1972) [15] investigated the asymptotic almost sure representation of a sample quantile for a stationary process of $\phi$-mixing random variables. He showed that Bahadur's (1966) [2] asymptotic almost sure representation of sample quantiles also holds under the $\phi$-mixing condition. One of the most recent papers in this context is $\mathrm{Wu}$ (2005) [17] who obtained Bahadur's representation for a class of linear and non-linear (scalar) processes. Oberhofer and Haupt (2005) [11] showed the asymptotic distribution of the unconditional quantile estimator and the joint asymptotic normality of several quantiles by using results on convex stochastic optimization and mixing properties of an indicator process.

In this note, we investigate the asymptotic behaviour of sample quantiles for a vector stationary process. The use of quantiles in statistical inference abound, in particular in the context of heavy tails where moments may not exist. They have been used for the estimation of parameters (Dominicy and Veredas (2012) [7] and Dominicy et al. (2012) [6]). Multivariate dependencies between financial products have often been computed with copulas. Fermanian and Scaillet (2003) [9] use sample marginal quantiles from time series data as a non-parametric method to estimate copulas. The 2007-2010 financial and the 2009-2012 European sovereign debt crises have highlighted the importance of tail -or rare- events. When they occur, their effect is spread over the system, creating tail correlation. Ricci and Veredas (2012) [12] introduce TailCoR, a new measure of tail correlation for financial time series that is based on sample marginal quantiles.

The classical approach to obtain limiting distributions for statistics of weakly dependent processes is to impose mixing conditions (i.e. $\alpha^{-}, \phi-, \psi_{-}$, and $\beta$-mixing). Those classical mixing conditions are interesting and lead to acute results. However, often they are not only difficult to be verified but require as well strong smoothness of the process, and so their 
range of applications in time series context is somewhat limited. A drastic example is an $\operatorname{AR}(1)$ process with iid Bernoulli innovations $\left(\varepsilon_{t}\right)$ (i.e. $\varepsilon_{t}= \pm 1$ with probability $1 / 2$ ). When $X_{t}=\frac{1}{2} X_{t-1}+\varepsilon_{t}$ the dependence amoung the variables $X_{t}$ decays obviously very fast but surprisingly this process is not mixing (see Rosenblatt (1985) [13]).

The inadequacy of classical mixing conditions in the time series context has lead to a number of new approaches for dealing with weak dependence in the last couple of years. One of these approaches is the so called $S$-mixing introduced by Berkes et al. (2009) [3]. $S$-mixing is attractive since its verification is almost immediate (it is a trivial exercise to verify it for the AR-processes) and it nests a large number of well-known and well-used econometric models such as linear processes (especially ARMA models), GARCH models and its extensions, and stochastic volatility models, among others. A remarkable property of $S$-mixing is the fact that it doesn't require any higher order moment assumptions to be verified. Since we are interested in quantiles and processes that are probably heavy-tailed, this is of particular interest. Furthermore, using the results of Berkes et al. (2009) [3] we avoid establishing Bahadur's (1966) [2] representation, which is a theoretically interesting result, but not necessary for the asymptotic normality of quantiles. We refer to Berkes et al. (2009) [3] for a number of examples within this framework.

The remaining sections are laid out as follows. In Section 2 we review briefly the $S$-mixing property and state the joint asymptotic distribution for marginal quantiles. Section 3 covers the Monte Carlo study and Section 4 concludes. The proof of the theorem, other technical results, and figures are relegated to the Appendix.

\section{Setup and main result}

Throughout this note, we assume that the $p$-dimensional process $\left\{\boldsymbol{X}_{t}, t \in \mathbb{Z}\right\}$ has the following form

$$
\boldsymbol{X}_{t}=f\left(\varepsilon_{t}, \varepsilon_{t-1}, \ldots\right)
$$

where $\left\{\varepsilon_{t}\right\}$ is an i.i.d. sequence taking values in a measurable space $\mathbb{S}$ and $f: \mathbb{S}^{\infty} \rightarrow \mathbb{R}^{p}$ is a measurable function. Representation (1) is quite natural in time series and it implies that the process $\left\{\boldsymbol{X}_{t}\right\}$ is strictly stationary and ergodic. As the aim is to show the asymptotic normality of the empirical quantile vector

$$
\left(q_{\tau_{1}, n}^{(1)}, \ldots, q_{\tau_{p}, n}^{(p)}\right)^{\prime}
$$

for given $\tau_{1}, \ldots, \tau_{p} \in[0,1]$, we need to impose stronger conditions on the structure of $\left\{\boldsymbol{X}_{t}\right\}$. We use the $S$-mixing condition introduced in Berkes et al. (2009) [3]. ${ }^{1}$

Definition 1 A random process $\left\{\boldsymbol{X}_{t}, t \in \mathbb{Z}\right\}$ is called $S$-mixing if it satisfies the following two conditions.

i) For any $t \in \mathbb{Z}$ and $m \in \mathbb{N}$, there exists some approximating random vectors $\boldsymbol{X}_{t m}$ such that $P\left(\left|\boldsymbol{X}_{t}-\boldsymbol{X}_{t m}\right| \geq \gamma_{m}\right) \leq \delta_{m}$, for some numerical sequences $\gamma_{m} \rightarrow 0$ and $\delta_{m} \rightarrow 0$.

ii) For any disjoint intervals $I_{1}, \ldots, I_{r}$ of integers and any positive integers $m_{1}, \ldots, m_{r}$, the vectors $\left\{\boldsymbol{X}_{t m_{1}}, t \in I_{1}\right\}, \ldots,\left\{\boldsymbol{X}_{t m_{r}}, t \in I_{r}\right\}$ are independent provided the separation between $I_{k}$ and $I_{l}$ is greater than $m_{k}+m_{l}$.

\footnotetext{
${ }^{1}$ Originally introduced for scalar processes, this notion of mixing is straightforwardly generalized to vectorvalued series.
} 
$S$-mixing requires approximating random vectors $\boldsymbol{X}_{t m}$ that can be constructed in various ways. Among them, we will use a coupling method. Let $\left\{\varepsilon_{t}^{(k)}, t \in \mathbb{Z}, k \in \mathbb{Z}\right\}$ be an i.i.d. array of random elements all having the same law as $\varepsilon_{0}$. Now we set the approximating random vectors as

$$
\left\{\boldsymbol{X}_{t m}, t \in \mathbb{Z}\right\}=\left\{f\left(\varepsilon_{t}, \varepsilon_{t-1}, \ldots, \varepsilon_{t-m}, \varepsilon_{t-m-1}^{(t)}, \ldots\right), t \in \mathbb{Z}\right\} .
$$

This way of construction leads $\boldsymbol{X}_{t m}$ 's to have same marginal distributions as those of $\boldsymbol{X}_{t}$ 's, while being now $m$-dependent. If the process is weakly dependent, then with increasing $m$ the approximations $\boldsymbol{X}_{t m}$ are expected to converge (in some sense to be specified) to $\boldsymbol{X}_{t}$.

Before stating the theorem, we need two assumptions. The first relates to the marginal distribution functions $F^{(i)}$, while the second relates to the dependence structure of $\boldsymbol{X}_{t}$.

Assumption 1 For any $i=1, \ldots, p$, the distribution $F^{(i)}(x)$ has a density $f^{(i)}(x)$ that is positive and continuous in a neighbourhood of $q_{\tau_{i}}^{(i)}$ and $f^{(i)}(x)$ is uniformly bounded by some constant $B$.

Assumption 2 The process $\left\{\boldsymbol{X}_{t}, t \in \mathbb{Z}\right\}$ has representation (1) and with approximations (2) it is $S$-mixing with coefficients $\gamma_{m}=\delta_{m}=O\left(m^{-A}\right), A>4$.

Equipped with the definition of $S$-mixing and the assumptions, we present the theorem.

Theorem 1 Let $\left\{\boldsymbol{X}_{t}\right\}$ be a stationary process satisfying Assumptions 1 and 2. Let us define $\boldsymbol{V}=\operatorname{diag}\left(f^{(1)}\left(q_{\tau_{1}}^{(1)}\right), \ldots, f^{(p)}\left(q_{\tau_{p}}^{(p)}\right)\right)$ and $\boldsymbol{Q}=\sum_{h \in \mathbb{Z}} E \boldsymbol{T}_{0} \boldsymbol{T}_{h}^{\prime}$ with

$$
\boldsymbol{T}_{k}=\left(I\left\{X_{k}^{(1)} \leq q_{\tau_{1}}^{(1)}\right\}-\tau_{1}, \ldots, I\left\{X_{k}^{(p)} \leq q_{\tau_{p}}^{(p)}\right\}-\tau_{p}\right)^{\prime} .
$$

Then

$$
\sqrt{n}\left(q_{\tau_{1}, n}^{(1)}-q_{\tau_{1}}^{(1)}, \ldots, q_{\tau_{p}, n}^{(p)}-q_{\tau_{p}}^{(p)}\right) \stackrel{\mathcal{D}}{\rightarrow} \mathcal{N}(\mathbf{0}, \Psi),
$$

where $\boldsymbol{\Psi}=\boldsymbol{V}^{-1} \boldsymbol{Q} \boldsymbol{V}^{-1}$. The element in the $i$-th row and $j$-th column of the matrix $\boldsymbol{\Psi}$ is given by

$$
\psi_{i j}=\frac{\sum_{h \in \mathbb{Z}}\left(P\left(\left\{X_{0}^{(i)} \leq q_{\tau_{i}}^{(i)}\right\} \cap\left\{X_{h}^{(j)} \leq q_{\tau_{j}}^{(j)}\right\}\right)-\tau_{i} \tau_{j}\right)}{f^{(i)}\left(q_{\tau_{i}}^{(i)}\right) f^{(j)}\left(q_{\tau_{j}}^{(j)}\right)} .
$$

\section{Monte Carlo study}

We carry out a Monte Carlo experiment to assess the finite sample performance of the sample quantiles in a bivariate setup. Extensions of this experiment to higher dimensions are straightforward but they do not add value added since we are interested in marginal quantiles. We generate 500 draws of 100 (small sample) and 1000 (large sample) observations from two bivariate dynamic models, one for the location (a VAR(1)) and another for the scale (a CCC-GARCH $(1,1))^{2}$ In both settings we assume that the vector of innovations $\boldsymbol{\epsilon}_{t}$ follows a multivariate Student-t distribution with zero location, identity dispersion matrix,

\footnotetext{
${ }^{2}$ The bivariate $\operatorname{VAR}(1)$ model is defined as $\boldsymbol{x}_{t}=\boldsymbol{c}+\boldsymbol{A} \boldsymbol{x}_{t-1}+\boldsymbol{\epsilon}_{t}$, where $\boldsymbol{c}$ is a $2 \times 1$ vector of intercepts, $\boldsymbol{A}$ is a $2 \times 2$ matrix and $\boldsymbol{\epsilon}_{t}$ is a $2 \times 1$ vector of innovations.
} 
and the degrees of freedom being either $\nu=10$ or $\nu=20$. Two remarks to these choices. First, $\nu=20$ produce moderate tails in the distribution of the innovations, while those for $\nu=10$ are fairly heavy. Second, the unconditional distribution of $\boldsymbol{x}_{t}$ has heavier tails in the $C C C-\operatorname{GARCH}(1,1)$ model than those of the innovations, and hence for $\nu=10$ the tail of the observations are heavier than those of the innovations. ${ }^{3}$

For the VAR(1) model, we set the vector of constants $\boldsymbol{c}$ equal to zero and $\boldsymbol{A}$ to

$$
\boldsymbol{A}=\left(\begin{array}{cc}
0.5 & 0.2 \\
0.2 & 0.5
\end{array}\right)
$$

As for the CCC-GARCH$(1,1)$, the correlation is 0.5 and the parameters for the conditional dispersions are given by $\boldsymbol{\theta}=\left[\omega_{1}, \alpha_{1}, \beta_{1}, \omega_{2}, \alpha_{2}, \beta_{2}\right]=[0.05,0.05,0.7,0.05,0.05,0.7]$. Thus, we consider 8 scenarios and for each we estimate the quantiles for $\tau=\{0.01,0.10,0.25,0.5\}$. Results are displayed in the form of $\mathrm{Q}-\mathrm{Q}$ plots (sample distribution of the 500 estimated quantiles against the Gaussian distribution) in Figures 1-4 in the Appendix. Each figure has two panels, for 100 and 1000 observations respectively. The first two figures are for the VAR(1) model, while the other two are for the CCC-GARCH $(1,1){ }^{4}$

Results are in line with the intuition. For the VAR, the sample distribution of the estimated quantiles is well approximated by the asymptotic distribution of 0.25 and 0.50 quantiles for any tail thickness and sample size. The sample distribution of extreme quantiles show slight departures from Gaussianity for $n=100$, in particular for $\nu=10$, but it improves substantially for $n=1000$. Similar conclusions are drawn for the CCC-GARCH $(1,1)$, except that, due to the volatility clustering, more observations are needed in the case of $\nu=10$ for the sample distribution to be closely represented by the asymptotic counterpart.

\section{Conclusions}

In this note we show the asymptotic normality of marginal sample quantiles for vector stationary processes under the $S$-mixing condition. The results obtained via Monte Carlo simulations confirm the theoretical result.

The bivariate CCC-GARCH(1,1) model is defined as $\boldsymbol{x}_{t}=\boldsymbol{H}_{t}^{1 / 2} \boldsymbol{\epsilon}_{t}$ where $\boldsymbol{\epsilon}_{t}$ is an i.i.d. vector standardized error process, and $\boldsymbol{H}_{t}=\left[h_{i j, t}\right]$ is the $2 \times 2$ conditional dispersion matrix of $\boldsymbol{x}_{t}$, expressed as $\boldsymbol{H}_{t}=\boldsymbol{D}_{t} \boldsymbol{P} \boldsymbol{D}_{t}$ where $\boldsymbol{D}_{t}=\operatorname{diag}\left(\boldsymbol{H}_{t}^{1 / 2}\right)$ and $\boldsymbol{P}=\left[\rho_{i j}\right]$ is positive definite with $\rho_{i i}=1$ for $i=1,2$. The diagonal elements follow a $\operatorname{GARCH}(1,1)$ model $h_{i i, t}=\omega_{i}+\alpha_{i} x_{i i, t-1}^{2}+\beta_{i} h_{i i, t-1}$, and the off-diagonal are given by $h_{i j, t}=h_{i i, t}^{1 / 2} h_{j j, t}^{1 / 2} \rho_{i j}$, for $1 \leq i \neq j \leq 2$.

${ }^{3}$ This reasoning follows the same lines as the well known fact that the unconditional distribution entailed by a Gaussian $\operatorname{GARCH}(1,1)$ has standardized kurtosis larger than 3.

${ }^{4}$ We did further simulations with different specifications of the conditional mean and variance. Results, available under request, do not change qualitatively the conclusions. 


\section{References}

[1] G. J. Babu and C. R. Rao. Joint asymptotic distribution of marginal quantiles and quantile functions in samples from quantile functions in samples from a multivariate population. Journal of Multivariate Analysis, 27:15-23, 1988.

[2] R. R. Bahadur. A note on quantiles in large samples. Annals of Mathematical Statistics, 37:577-580, 1966.

[3] I. Berkes, S. Hörmann, and J. Schauer. Asymptotic results for the empirical process of stationary sequences. Stochastic Processes and their Applications, 119:1298-1324, 2009.

[4] P. Billingsley. Convergence of probability measures. Wiley Series in Probability and Statistics: Probability and Statistics. John Wiley \& Sons Inc., New York, second edition, 1999. A Wiley-Interscience Publication.

[5] H. Cramér. Mathematical Methods of Statistics. Princeton Mathematical Series, vol. 9. Princeton University Press, Princeton, N. J., 1946.

[6] Y. Dominicy, H. Ogata, and D. Veredas. Inference for vast dimensional elliptical distributions. ECARES WP 2010/29, 2012.

[7] Y. Dominicy and D. Veredas. The method of simulated quantiles. Journal of Econometrics, forthcoming, 2012.

[8] K. Dutta and P. K. Sen. On the Bahadur representation of sample quantiles in some stationary multivariate autoregressive processes. Journal of Multivariate Analysis, 1(2):186-198, 1971.

[9] J.D. Fermanian and O. Scaillet. Nonparametric estimation of copulas for time series. Journal of Risk, $5: 25-54,2003$.

[10] T. L. Lai. Reproducing kernel Hilbert spaces and the law of the iterated logarithm for Gaussian processes. Zeitschrift für Wahrscheinlichkeitstheorie und Verwandte Gebiete, 29:7-19, 1974.

[11] W. Oberhofer and H. Haupt. The asymptotic distribution of the unconditional quantile estimator under dependence. Statistics and Probability Letters, 73:243-250.

[12] L. Ricci and D. Veredas. Tailcor. ECARES WP 2012/16, 2012.

[13] M. Rosenblatt. Stationary sequences and random fields. Birkhäuser Boston Inc., Boston, MA, 1985.

[14] P. K. Sen. Asymptotic normality of sample quantiles for $m$-dependent processes. Annals of Mathematical Statistics, 39:1724-1730, 1968.

[15] P. K. Sen. On the bahadur representation of sample quantiles for sequences of $\phi-$ mixing random variables. Journal of Multivariate Analysis, 2:77-95, 1972.

[16] W. Stute and G. Schumann. A general Glivenko-Cantelli theorem for stationary sequences of random observations. Scandinavian Journal of Statistics. Theory and Applications, 7(2):102-104, 1980.

[17] W. B. Wu. On the Bahadur representation of sample quantiles for dependent sequences. Annals of Statistics, 33:1934-1963, 2005. 


\section{Appendix: proofs}

For simplicity, we will henceforth use the following notation $X_{t}=X_{t}^{(i)}, F=F^{(i)}$ and $q_{\tau}=q_{\tau}^{(i)}$ for some generic component, its distribution and its $\tau$-quantile, respectively. Let us further note that, since all marginal distributions are continuous, the event $\left\{X_{t}=X_{s}\right\}$ has probability zero if $t \neq s$. This means that the sample points $X_{1}, \ldots, X_{n}$ are all distinct and thus the jumps of the empirical distribution function have size $1 / n$. Consequently

$$
\left|F_{n}\left(q_{\tau, n}\right)-\tau\right| \leq n^{-1} \quad \text { a.s. }
$$

Before giving the proof of our main theorem, we need to state and prove some lemmas.

Lemma 1 Under the Assumptions 1 and 2 we have

$$
\left(q_{\tau_{1}, n}^{(1)}, \ldots, q_{\tau_{p}, n}^{(p)}\right)^{\prime} \rightarrow\left(q_{\tau_{1}}^{(1)}, \ldots, q_{\tau_{p}}^{(p)}\right)^{\prime} \quad \text { a.s. }
$$

Proof. It is sufficient to give the proof component-wise. Since $F(x)$ is continuous, monotonously increasing and strictly monotone in a neighbourhood of $q_{\tau}$ we have $q_{\tau, n} \rightarrow q_{\tau}$ if and only if $F\left(q_{\tau, n}\right) \rightarrow$ $F\left(q_{\tau}\right)$. Thus we evaluate

$$
\begin{aligned}
\left|F\left(q_{\tau, n}\right)-F\left(q_{\tau}\right)\right| & \leq\left|F\left(q_{\tau, n}\right)-F_{n}\left(q_{\tau, n}\right)\right|+\left|F_{n}\left(q_{\tau, n}\right)-F\left(q_{\tau}\right)\right| \\
& \leq \sup _{x \in \mathbb{R}}\left|F(x)-F_{n}(x)\right|+\left|F_{n}\left(q_{\tau, n}\right)-\tau\right| .
\end{aligned}
$$

Now the result follows from the Glivenco-Cantelli theorem for stationary processes (see e.g. Stute and Schumann (1980) [16]) and (3).

Our next lemma is a special case of the main result in Berkes et al. (2009) [3]. To state it we introduce

$$
R(x, n)=\sum_{k=1}^{n} Y_{k}(x) \quad \text { where } \quad Y_{k}(x)=I\left\{X_{k} \leq x\right\}-F(x), \quad x \in \mathbb{R} .
$$

Lemma 2 Under Assumptions 1 and 2 the series

$$
\Gamma\left(x, x^{\prime}\right)=\sum_{-\infty<k<\infty} E Y_{0}(x) Y_{k}\left(x^{\prime}\right)
$$

converges absolutely for every choice of parameters $\left(x, x^{\prime}\right) \in \mathbb{R}^{2}$. Moreover, there exists a two-parameter Gaussian process $K(x, n)$ such that $E K(x, n)=0$ and $E K(x, n) K\left(x^{\prime}, n^{\prime}\right)=\left(n \wedge n^{\prime}\right) \Gamma\left(x, x^{\prime}\right)$ and for some $\varepsilon>0$

$$
\sup _{0 \leq n \leq N} \sup _{x \in \mathbb{R}}|R(x, n)-K(x, n)|=o\left(N^{1 / 2}(\log N)^{-\varepsilon}\right) \quad \text { a.s. }
$$

The next lemma will allow us to deduce asymptotic normality for the quantiles from the empirical process.

Lemma 3 There exists a $q_{\tau, n}^{*}$ in the interval bounded by $q_{\tau}$ and $q_{\tau, n}$ such that we have the following representation:

$$
\sqrt{n}\left(F\left(q_{\tau}\right)-F_{n}\left(q_{\tau}\right)\right)=\sqrt{n} f\left(q_{\tau, n}^{*}\right)\left(q_{\tau, n}-q_{\tau}\right)+o_{P}(1) .
$$

Proof. By the mean value theorem we have

$$
F\left(q_{\tau, n}\right)-F\left(q_{\tau}\right)=f\left(q_{\tau, n}^{*}\right)\left(q_{\tau, n}-q_{\tau}\right) .
$$

Noting that $F\left(q_{\tau}\right)=\tau$ we get via (3) that the left hand side above is equal to $F\left(q_{\tau, n}\right)-F_{n}\left(q_{\tau, n}\right)+$ $O_{p}(1 / n)$. It remains to show that 


$$
\sqrt{n}\left(\left[F\left(q_{\tau, n}\right)-F_{n}\left(q_{\tau, n}\right)\right]-\left[F\left(q_{\tau}\right)-F_{n}\left(q_{\tau}\right)\right]\right)=o_{p}(1) .
$$

By Lemma 2 we infer that there exists an $\varepsilon>0$ and a Gaussian process $K(x, n)$ such that

$$
\sup _{x \in \mathbb{R}}\left|\sqrt{n}\left(F_{n}(x)-F(x)\right)-\frac{1}{\sqrt{n}} K(x, n)\right|=O_{p}\left((\log n)^{-\varepsilon}\right) .
$$

Hence (7) follows if $\left|\frac{1}{\sqrt{n}} K\left(q_{\tau}, n\right)-\frac{1}{\sqrt{n}} K\left(q_{\tau_{n}}, n\right)\right| \stackrel{\mathcal{P}}{\rightarrow} 0$. In the proof of Lemma 6 of Berkes et al. (2009) [3] it is shown that there is a $\tau>0$ such that

$$
E\left|\frac{1}{\sqrt{n}} K(x, n)-\frac{1}{\sqrt{n}} K\left(x^{\prime}, n\right)\right|^{2} \leq C\left|x-x^{\prime}\right|^{\tau} .
$$

This implies (see e.g. Lemma 2 in Lai (1974) [10]) that the processes $\left\{n^{-1 / 2} K(x, n), x \in \mathbb{R}\right\}$ have continuous sample paths. Since the law of $\left\{n^{-1 / 2} K(x, n), x \in \mathbb{R}\right\}$ is independent of $n$, we get in view of Lemma 1 the proof by routine arguments.

Via the Cramér-Wold device, the next lemma gives asymptotic normality of the marginal empirical distribution functions evaluated at fixed arguments.

Lemma 4 Under Assumptions 1 and 2 we have that for any $p$-vectors $\boldsymbol{v}=\left(v_{1}, \ldots, v_{p}\right)^{\prime}$ with $|\boldsymbol{v}|=1$ and $\boldsymbol{x}=\left(x_{1}, \ldots, x_{p}\right)^{\prime}$ that

$$
Z_{n}:=\sqrt{n} \sum_{i=1}^{p} v_{i}\left(F_{n}^{(i)}\left(x_{i}\right)-F^{(i)}\left(x_{i}\right)\right) \stackrel{\mathcal{D}}{\rightarrow} N\left(0, \boldsymbol{v}^{\prime} \boldsymbol{Q v}\right),
$$

where $\boldsymbol{Q}$ is defined in Theorem 1 .

Proof. Define

$$
\eta_{k}=\sum_{i=1}^{p} v_{i}\left(I\left\{X_{k}^{(i)} \leq x_{i}\right\}-F^{(i)}\left(x_{i}\right)\right)
$$

and

$$
\eta_{k m}=\sum_{i=1}^{p} v_{i}\left(I\left\{X_{k m}^{(i)} \leq x_{i}\right\}-F^{(i)}\left(x_{i}\right)\right)
$$

where $X_{k m}^{(i)}$ are defined as in (2). Then $Z_{n}=n^{-1 / 2} \sum_{k=1}^{n} \eta_{k}$. By the Cauchy-Schwartz inequality we have

$$
\begin{aligned}
E\left|\eta_{k}-\eta_{k m}\right|^{2} & \leq \sum_{i=1}^{p} E\left|I\left\{X_{k}^{(i)} \leq x_{i}\right\}-I\left\{X_{k m}^{(i)} \leq x_{i}\right\}\right|^{2} \\
& \left.\leq \sum_{i=1}^{p} E\left(I\left\{X_{k}^{(i)} \in\left[x_{i}-\delta, x_{i}+\delta\right]\right)\right\}+I\left\{\left|X_{k}^{(i)}-X_{k m}^{(i)}\right|>\delta\right\}\right) \\
& \leq p\left(2 B \delta+P\left(\left|\boldsymbol{X}_{k}-\boldsymbol{X}_{k m}\right|>\delta\right) .\right.
\end{aligned}
$$

Choosing $\delta=\delta_{m}=m^{-4}$ we obtain that $\sum_{m>1}\left(E\left|\eta_{k}-\eta_{k m}\right|^{2}\right)^{1 / 2}<\infty$. By a slightly adapted version of Theorem 19.3. in Billingsley (1999) [4] this implies that the sequence $\left\{\eta_{k}\right\}$ satisfies the central limit theorem: 


$$
\frac{1}{\sqrt{n}} \sum_{k=1}^{n} \eta_{k} \stackrel{\mathcal{D}}{\rightarrow} N\left(0, \sigma^{2}\right)
$$

where $\sigma^{2}=\sum_{h \in \mathbb{Z}} \operatorname{Cov}\left(\eta_{0}, \eta_{h}\right)$. The claim is now immediate.

This leads to the proof of the main theorem.

Proof of Theorem 1. Lemma 1 shows that under our assumptions

$$
f\left(q_{\tau, n}^{*}\right) \stackrel{\mathcal{P}}{\rightarrow} f\left(q_{\tau}\right)>0 .
$$

A routine application of the Cramér-Wold device and Slutzky's theorem to Lemma 3 and Lemma 4 yields the desired asymptotic normality of the empirical quantiles. 


\section{Appendix: figures}

Figure 1: $\operatorname{VAR}(1)$ wiTh $\nu=10$
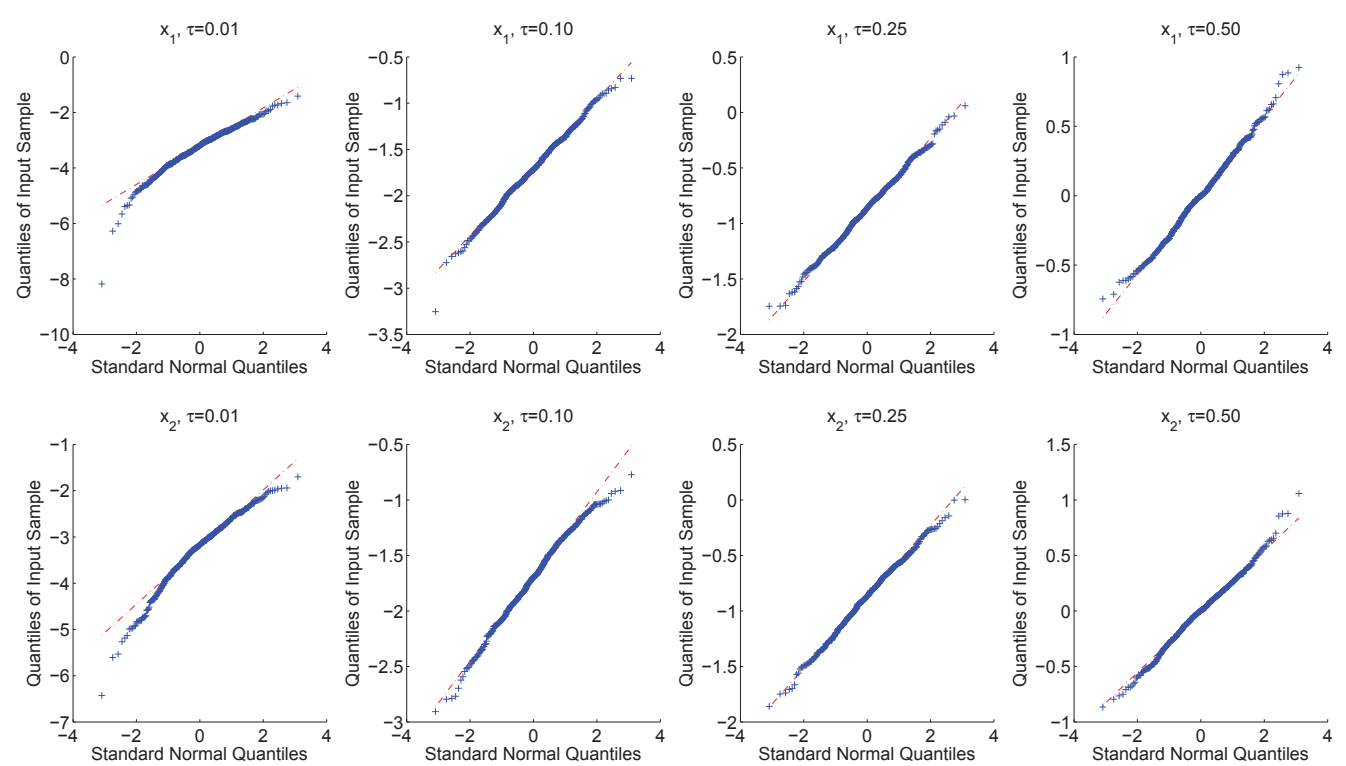

(a) $\mathrm{n}=100$
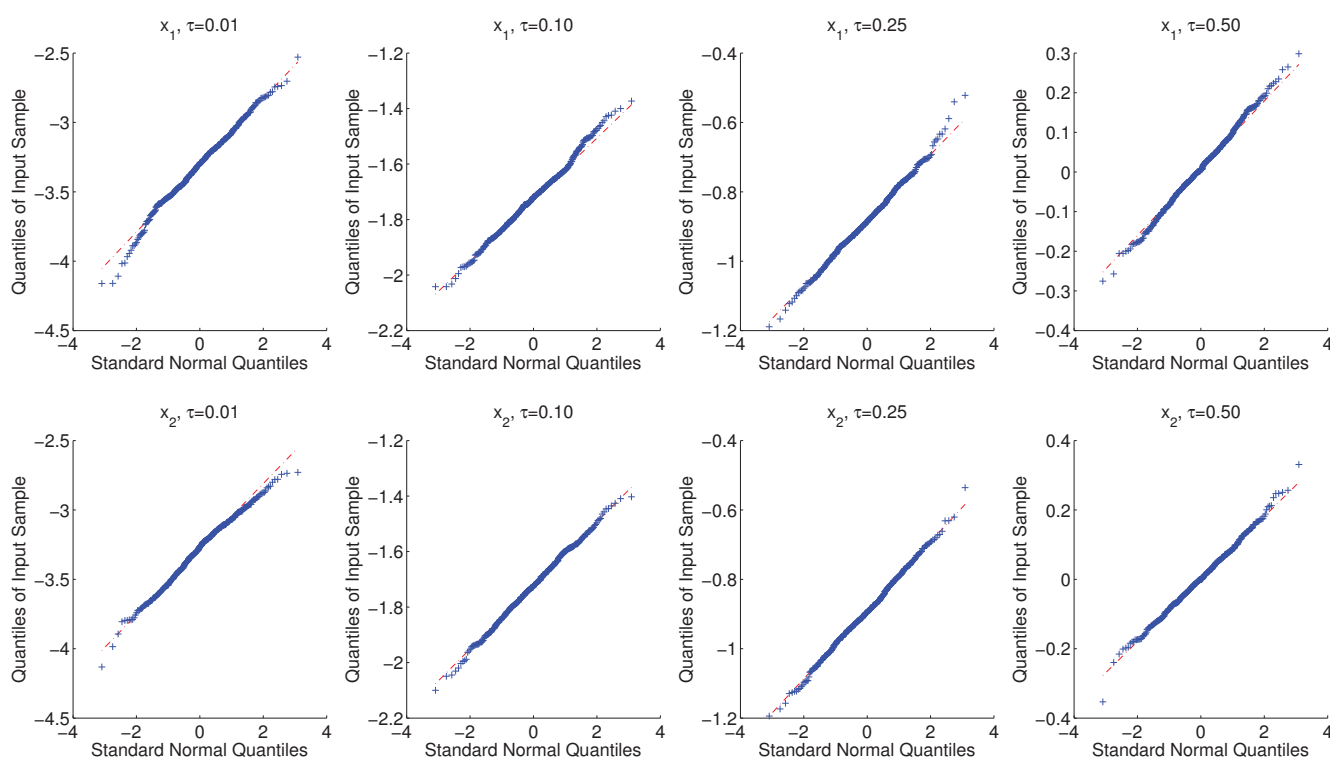

(b) $n=1000$ 
Figure 2: $\operatorname{VAR}(1)$ WITH $\nu=20$
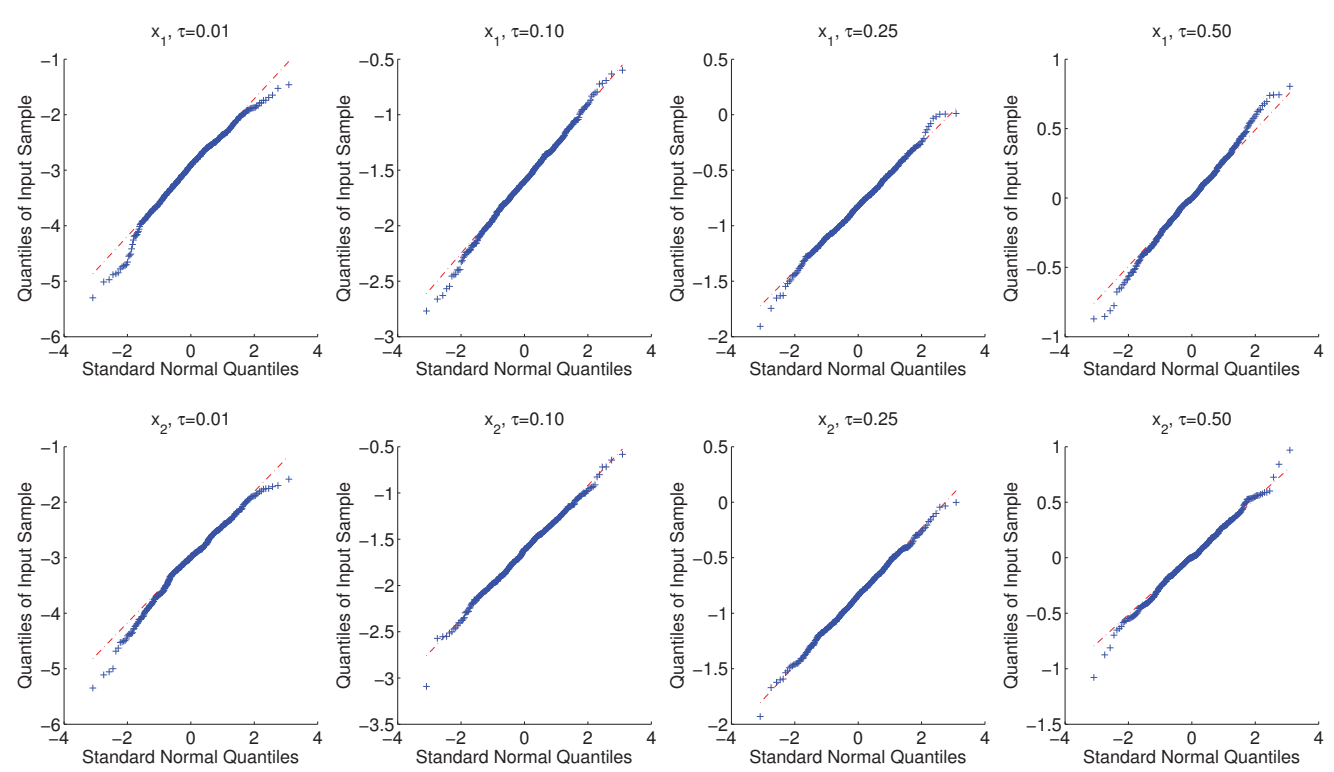

(a) $\mathrm{n}=100$
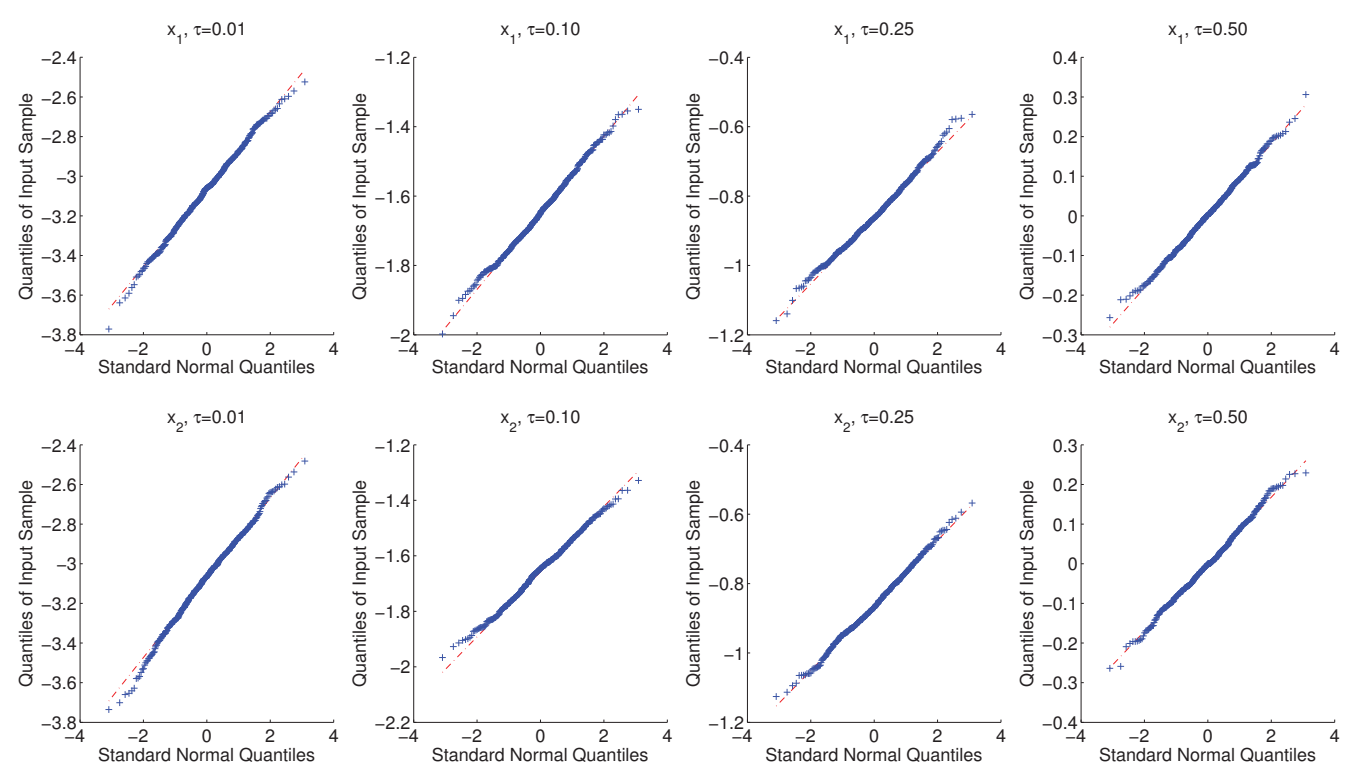

(b) $\mathrm{n}=1000$ 
Figure 3: CCC-GARCH(1,1) WITH $\nu=10$
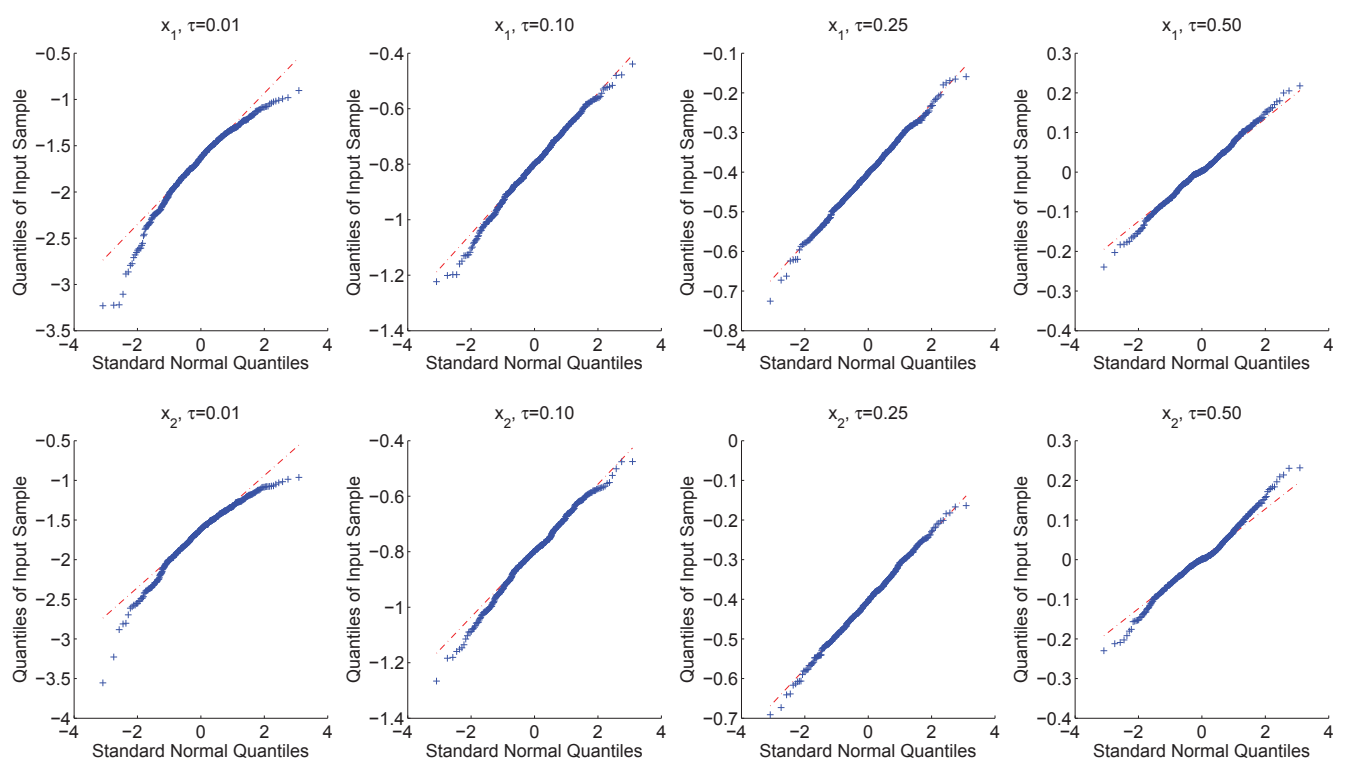

(a) $\mathrm{n}=100$
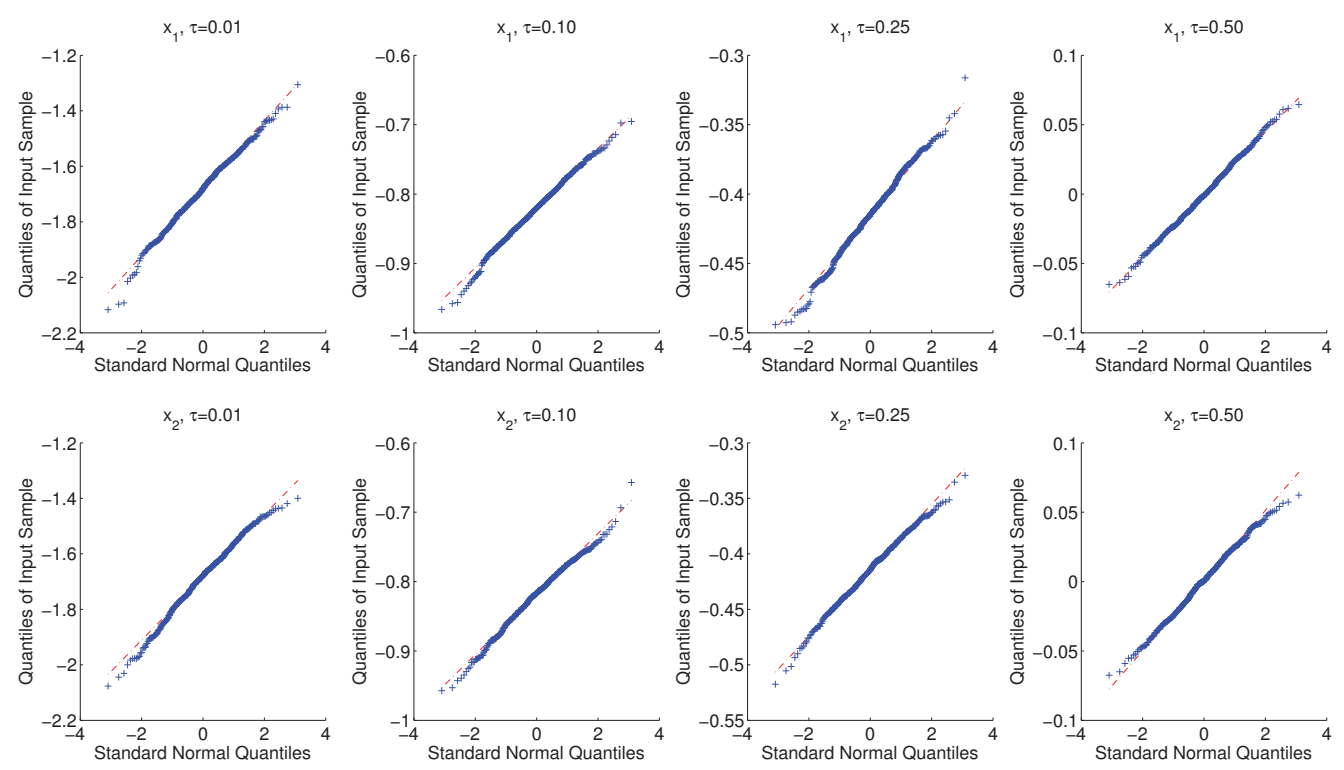

(b) $\mathrm{n}=1000$ 
Figure 4: CCC-GARCH(1,1) WITH $\nu=20$
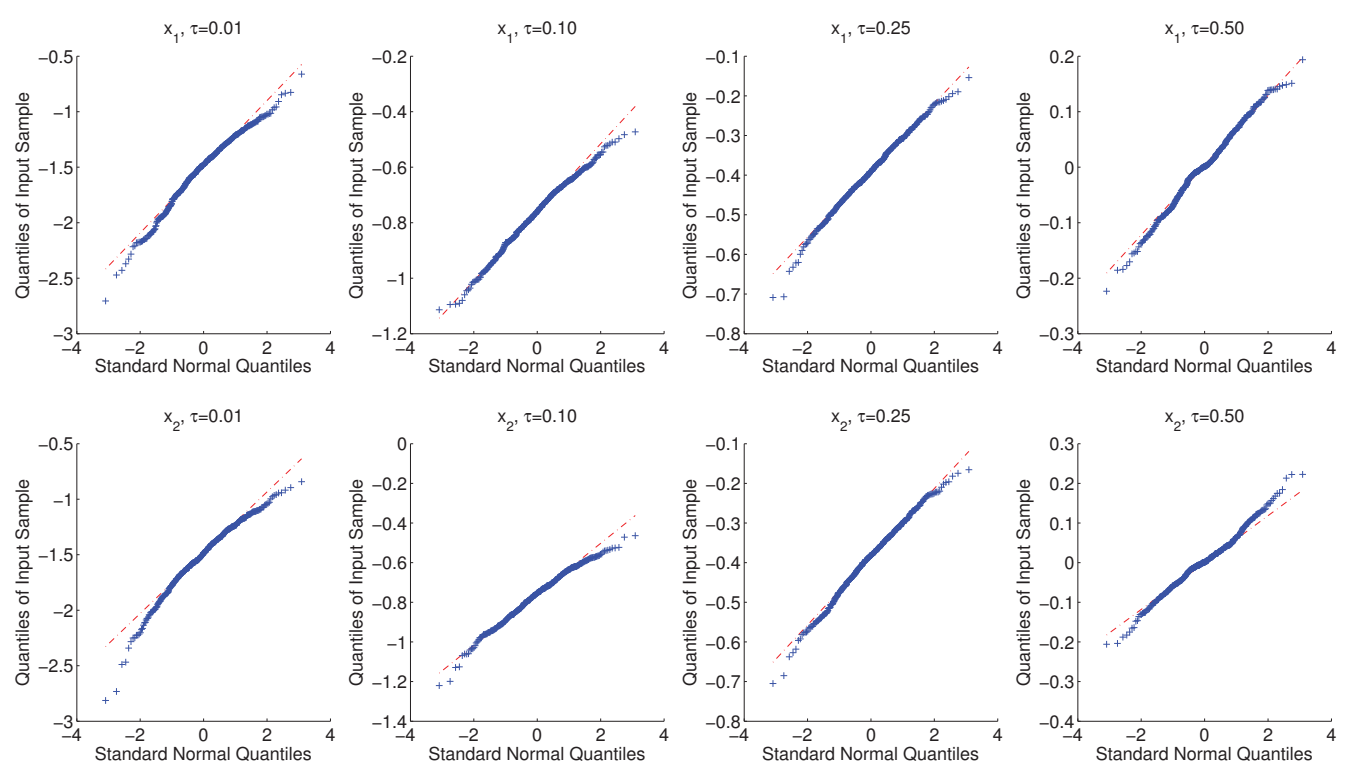

(a) $\mathrm{n}=100$
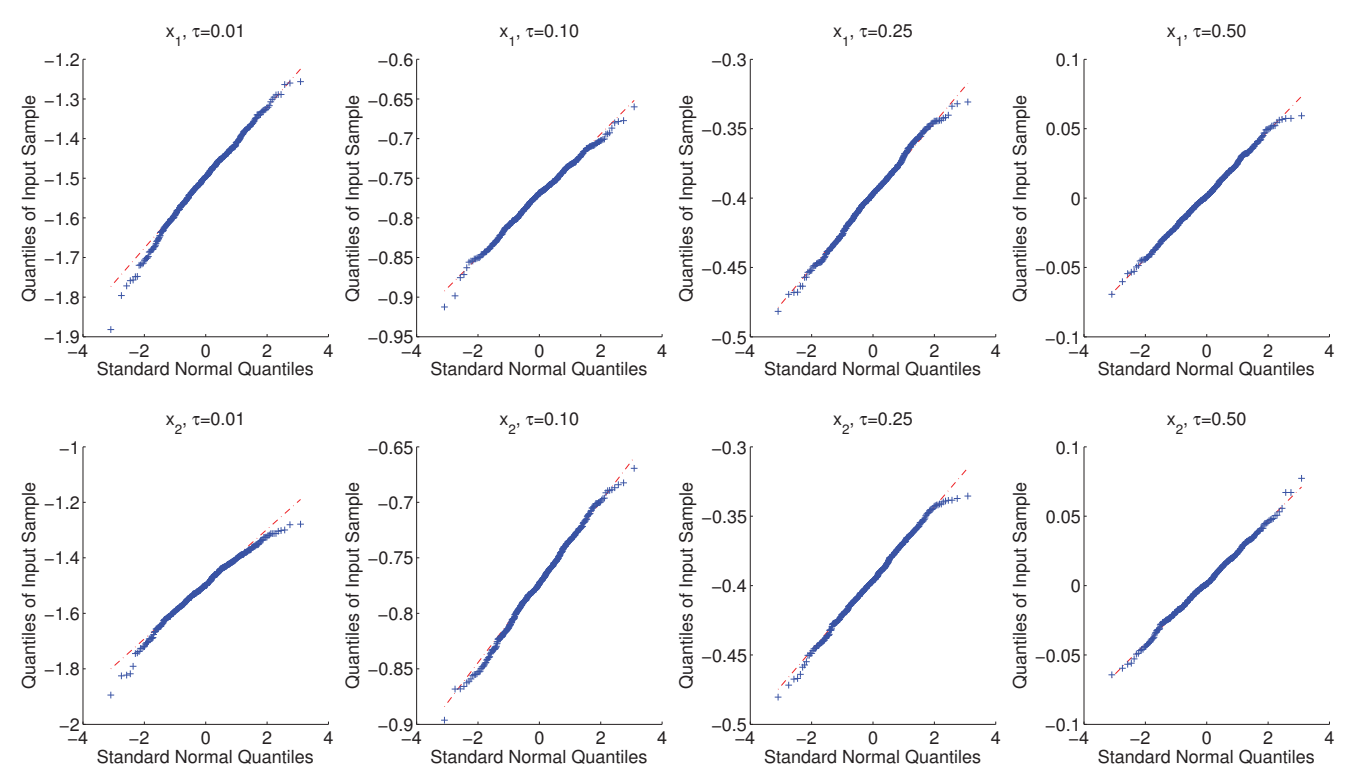

(b) $\mathrm{n}=1000$ 
BANCO DE ESPAÑA PUBLICATIONS

\author{
WORKING PAPERS
}

1101 GIACOMO MASIER and ERNESTO VILLANUEVA: Consumption and initial mortgage conditions: evidence from survey data.

1102 PABLO HERNÁNDEZ DE COS and ENRIQUE MORAL-BENITO: Endogenous fiscal consolidations

1103 CÉSAR CALDERÓN, ENRIQUE MORAL-BENITO and LUIS SERVÉN: Is infrastructure capital productive? A dynamic heterogeneous approach.

1104 MICHAEL DANQUAH, ENRIQUE MORAL-BENITO and BAZOUMANA OUATTARA: TFP growth and its determinants: nonparametrics and model averaging.

1105 JUAN CARLOS BERGANZA and CARMEN BROTO: Flexible inflation targets, forex interventions and exchange rate volatility in emerging countries.

1106 FRANCISCO DE CASTRO, JAVIER J. PÉREZ and MARTA RODRÍGUEZ VIVES: Fiscal data revisions in Europe.

1107 ANGEL GAVILÁN, PABLO HERNÁNDEZ DE COS, JUAN F. JIMENO and JUAN A. ROJAS: Fiscal policy, structural reforms and external imbalances: a quantitative evaluation for Spain.

1108 EVA ORTEGA, MARGARITA RUBIO and CARLOS THOMAS: House purchase versus rental in Spain.

1109 ENRIQUE MORAL-BENITO: Dynamic panels with predetermined regressors: likelihood-based estimation and Bayesian averaging with an application to cross-country growth.

1110 NIKOLAI STÄHLER and CARLOS THOMAS: FiMod - a DSGE model for fiscal policy simulations.

1111 ÁLVARO CARTEA and JOSÉ PENALVA: Where is the value in high frequency trading?

1112 FILIPA SÁ and FRANCESCA VIANI: Shifts in portfolio preferences of international investors: an application to sovereign wealth funds.

1113 REBECA ANGUREN MARTíN: Credit cycles: Evidence based on a non-linear model for developed countries.

1114 LAURA HOSPIDO: Estimating non-linear models with multiple fixed effects: A computational note.

1115 ENRIQUE MORAL-BENITO and CRISTIAN BARTOLUCCI: Income and democracy: Revisiting the evidence.

1116 AGUSTÍN MARAVALL HERRERO and DOMINGO PÉREZ CAÑETE: Applying and interpreting model-based seasonal adjustment. The euro-area industrial production series.

1117 JULIO CÁCERES-DELPIANO: Is there a cost associated with an increase in family size beyond child investment? Evidence from developing countries.

1118 DANIEL PÉREZ, VICENTE SALAS-FUMÁS and JESÚS SAURINA: Do dynamic provisions reduce income smoothing using loan loss provisions?

1119 GALO NUÑO, PEDRO TEDDE and ALESSIO MORO: Money dynamics with multiple banks of issue: evidence from Spain 1856-1874

1120 RAQUEL CARRASCO, JUAN F. JIMENO and A. CAROLINA ORTEGA: Accounting for changes in the Spanish wage distribution: the role of employment composition effects.

1121 FRANCISCO DE CASTRO and LAURA FERNÁNDEZ-CABALLERO: The effects of fiscal shocks on the exchange rate in Spain.

1122 JAMES COSTAIN and ANTON NAKOV: Precautionary price stickiness.

1123 ENRIQUE MORAL-BENITO: Model averaging in economics.

1124 GABRIEL JIMÉNEZ, ATIF MIAN, JOSÉ-LUIS PEYDRÓ AND JESÚS SAURINA: Local versus aggregate lending channels: the effects of securitization on corporate credit supply.

1125 ANTON NAKOV and GALO NUÑO: A general equilibrium model of the oil market.

1126 DANIEL C. HARDY and MARÍA J. NIETO: Cross-border coordination of prudential supervision and deposit guarantees.

1127 LAURA FERNÁNDEZ-CABALLERO, DIEGO J. PEDREGAL and JAVIER J. PÉREZ: Monitoring sub-central government spending in Spain.

1128 CARLOS PÉREZ MONTES: Optimal capital structure and regulatory control.

1129 JAVIER ANDRÉS, JOSÉ E. BOSCÁ and JAVIER FERRI: Household debt and labour market fluctuations.

1130 ANTON NAKOV and CARLOS THOMAS: Optimal monetary policy with state-dependent pricing.

1131 JUAN F. JIMENO and CARLOS THOMAS: Collective bargaining, firm heterogeneity and unemployment.

1132 ANTON NAKOV and GALO NUÑO: Learning from experience in the stock market.

1133 ALESSIO MORO and GALO NUÑO: Does TFP drive housing prices? A growth accounting exercise for four countries.

1201 CARLOS PÉREZ MONTES: Regulatory bias in the price structure of local telephone services. 
1202 MAXIMO CAMACHO, GABRIEL PEREZ-QUIROS and PILAR PONCELA: Extracting non-linear signals from several economic indicators.

1203 MARCOS DAL BIANCO, MAXIMO CAMACHO and GABRIEL PEREZ-QUIROS: Short-run forecasting of the euro-dollar exchange rate with economic fundamentals.

1204 ROCIO ALVAREZ, MAXIMO CAMACHO and GABRIEL PEREZ-QUIROS: Finite sample performance of small versus large scale dynamic factor models.

1205 MAXIMO CAMACHO, GABRIEL PEREZ-QUIROS and PILAR PONCELA: Markov-switching dynamic factor models in real time.

1206 IGNACIO HERNANDO and ERNESTO VILLANUEVA: The recent slowdown of bank lending in Spain: are supply-side factors relevant?

1207 JAMES COSTAIN and BEATRIZ DE BLAS: Smoothing shocks and balancing budgets in a currency union.

1208 AITOR LACUESTA, SERGIO PUENTE and ERNESTO VILLANUEVA: The schooling response to a sustained Increase in low-skill wages: evidence from Spain 1989-2009.

1209 GABOR PULA and DANIEL SANTABÁRBARA: Is China climbing up the quality ladder?

1210 ROBERTO BLANCO and RICARDO GIMENO: Determinants of default ratios in the segment of loans to households in Spain.

1211 ENRIQUE ALBEROLA, AITOR ERCE and JOSÉ MARÍA SERENA: International reserves and gross capital flows. Dynamics during financial stress.

1212 GIANCARLO CORSETTI, LUCA DEDOLA and FRANCESCA VIANI: The international risk-sharing puzzle is at businesscycle and lower frequency.

1213 FRANCISCO ALVAREZ-CUADRADO, JOSE MARIA CASADO, JOSE MARIA LABEAGA and DHANOOS SUTTHIPHISAL: Envy and habits: panel data estimates of interdependent preferences.

1214 JOSE MARIA CASADO: Consumption partial insurance of Spanish households.

1215 J. ANDRÉS, J. E. BOSCÁ and J. FERRI: Household leverage and fiscal multipliers.

1216 JAMES COSTAIN and BEATRIZ DE BLAS: The role of fiscal delegation in a monetary union: a survey of the political economy issues.

1217 ARTURO MACÍAS and MARIANO MATILLA-GARCÍA: Net energy analysis in a Ramsey-Hotelling growth model.

1218 ALFREDO MARTÍN-OLIVER, SONIA RUANO and VICENTE SALAS-FUMÁS: Effects of equity capital on the interest rate and the demand for credit. Empirical evidence from Spanish banks.

1219 PALOMA LÓPEZ-GARCÍA, JOSÉ MANUEL MONTERO and ENRIQUE MORAL-BENITO: Business cycles and investment in intangibles: evidence from Spanish firms.

1220 ENRIQUE ALBEROLA, LUIS MOLINA andPEDRO DEL RÍO: Boom-bust cycles, imbalances and discipline in Europe.

1221 CARLOS GONZÁLEZ-AGUADO and ENRIQUE MORAL-BENITO: Determinants of corporate default: a BMA approach.

1222 GALO NUÑO and CARLOS THOMAS: Bank leverage cycles.

1223 YUNUS AKSOY and HENRIQUE S. BASSO: Liquidity, term spreads and monetary policy.

1224 FRANCISCO DE CASTRO and DANIEL GARROTE: The effects of fiscal shocks on the exchange rate in the EMU and differences with the US.

1225 STÉPHANE BONHOMME and LAURA HOSPIDO: The cycle of earnings inequality: evidence from Spanish social security data.

1226 CARMEN BROTO: The effectiveness of forex interventions in four Latin American countries.

1227 LORENZO RICCI and DAVID VEREDAS: TailCoR.

1228 YVES DOMINICY, SIEGFRIED HÖRMANN, HIROAKI OGATA and DAVID VEREDAS: Marginal quantiles for stationary processes.

\begin{tabular}{|r|c|}
\hline BANCODE ESPANA & $\begin{array}{c}\text { Unidad de Servicios Auxiliares } \\
\text { Alcalá, 48 }-28014 \text { Madrid } \\
\text { Telephone }+34913386360 \\
\text { Eurosistema }\end{array}$ \\
E-mail: publicaciones@bde.es \\
www.bde.es
\end{tabular}

